\title{
The Detection of Changes in Land Use and Land Cover of Al-Kut City using Geographic Information System (GIS)
}

\author{
Fatima Asaad Tayeb ${ }^{1 *}$, Ahmed Kareem Jebur ${ }^{1}$ and Husham H. Rashid ${ }^{2}$ \\ ${ }^{1}$ Department of Surveying Techniques, Kut Technical Institute, Middle Technical University, Baghdad, Iraq \\ ${ }^{2}$ Middle Technical University, Institute of Technology, Baghdad, Iraq
}

\begin{abstract}
Models of digital elevation (DEMs), which provide elevation information for the ground surface of the catchment, are core components of computer-based analyzes for drainage basins. Many production methods are available, including contour interpolation, DGPS (Differential Global Positioning System) interpolation, and digital photogrammetry techniques. However, data on the precision and often contradictory nature of these three techniques are sparse. This study aims at identifying some of the contributing factors and comparing the accuracy of various approaches quantitatively. Changes in land coverage break ecosystem cycles, which may directly affect land ability to sustain human activity resulting in long-term trends of decline and inter-annual variability. It can be monitored at a spatial level of detail to enable the study of human-induced changes. Remote sensing techniques (RS) and geographical information system (GIS) methods have been used to extract the spatial and temporal changes of urban land use in the city of Al-Kut. The land sat satellite images taken in periods encompassing 1997, 2007, and 2017 are used. As a result, the city has lost a large part of its urban specificity and gained randomness and disorder in most of its residential neighborhoods, which was especially exacerbated after the change in the governing system in 2003. The results show an increase of $314 \%$ and $219 \%$ in industrial and residential areas, respectively, whereas agricultural land and open spaces have decreased by $66 \%$ and $32 \%$. The data analysis reveals a diagnostic relationship between land-use conversion and socio-economic drivers. This

ARTICLE INFO

Article history:

Received: 30 March 2021

Accepted: 05 July 2021

Published: 04 January 2022

DOI: https://doi.org/10.47836/pjst.30.1.40 research sheds light on the total area changes of the Al-Kut city before and after 2003. It highlights the significant destruction of the city life, which was established over almost three centuries.
\end{abstract}

E-mail addresses:

nooralhudaiairaqi@gmail.com (Fatima Asaad Tayeb) ahemd.gis@gmail.com (Ahmed Kareem Jebur)

Husham.HRashid@gmail.com (Husham H. Rashid)

* Corresponding author
Keywords: Chemical impacts, GIS, remote sensing, social factors 


\section{INTRODUCTION}

Satellite remote-sensing techniques have been successfully used in detecting and monitoring land cover change at various scales (Xiao \& Weng, 2007). However, there is an increasing need to develop the methodology of detecting changes in land cover using satellite imaging with the increasing importance of accurate and timely information that describe the nature of land resources and changes over time, especially in fast-growing urban areas (Popovici et al., 2013).

Land resources are increasingly scarce, and this is particularly true for land available for primary biomass production or purposes related to conservation. As a result, competing land uses are becoming more critical and frequent, resulting in more complex conflicts of interest. In addition, there are ongoing pressures of urban expansion competing with agricultural enterprises and recreational demands on the fringes of the urban areas. Such situations often lead to a rapid increase in the economic value of land, and land tenure becomes an important political issue (Prakasam et al., 2010).

Error analysis of many datasets is often confusing for some users because of not entirely or universally understanding error statistics. The most commonly used root mean squared error measurement (RMS error or RMSE) is at the forefront of this issue. Often users complain and misunderstand this error measure, particularly with regard to Global Positioning Systems (GPS). Error-values are commonly cited as 30 meters, which many consumers consider to be a maximal error, not RMS error, for GPS readings (previous to the elimination of Selective Availability). Many consumers still do not understand that a systemic error is not part of the cited RMSE value if the overwhelming error caused for GPS may be a systemic error. Inappropriate data collection is a classic source for systematic error in GPS systems, which can cause systemic errors in GPS readings of more than 1000 m of magnitude. Differential GPS (DGPS). The reads have errors in various quantities and their mistaken functions (Carry Phase (CP) corrections, the hardware involved, device rounding errors, atmospheric differences, base station-to-rover reach, satellite visibility, and multi-path errors, among others). Differential GPS(DGPS) is not prone to errors. A thorough description of DGPS source errors is given. Failed DEM analysis by interpolation obtained from contour data often continues to focus on the use of RMSE. This value is reasonably easy to calculate and provides an outstanding indicator of the exactness when properly made. Sadly, the end-users who manufacture DEMs have little, if any, the idea of error measuring and problems in this way is frequent.

The production of DMS can also be done with digital photogrammetry. Usually, the user can carry out systematic and thorough error analysis of findings through software developed to collect data from aerial photography. However, such software continues to be sophisticated and requires the expertise of the user. This sophistication and the limited potential demand aim to make this program costly, limiting the use of this DEM production 
process further. Other DEM sources such as LIDAR (Light Detection and Ranging) and interferometry radar are also available. However, these are relatively new approaches to DEM and, despite their precision and resolution benefits compared to more conventional approaches, have not yet gained widespread use. In general, the precision and shortcomings of these modern approaches are clearly articulated. However, because few conventional methods users understand the flaw in the actual data they use, they struggle to comprehend the benefits of such data sources, which may be reliable. This study attempts to offer an image of the spatial changes of urban land use in the residential, commercial, industrial areas in the Al-Kut city over four decades and evaluate whether these modifications have been negative or positive. Al-Kut city is the capital of Al-Kut district in Wassit Governorate of Iraq, shown in Figure 1. Al-Kut city is bounded between $45^{\circ} 46^{\prime} 00^{\prime \prime}$ to $45^{\circ} 53^{\prime} 20^{\prime \prime}$ E and $32^{\circ} 27^{\prime} 00^{\prime \prime}$ to $32^{\circ} 34^{\prime} 00^{\prime \prime} \mathrm{N}$ coordinates. It covers an area of about $5640 \mathrm{~km}^{2}$. Al-Kut city is located along the main highway connecting Baghdad with Amarah in the south, about 170 km south-east of Baghdad and $150 \mathrm{~km}$ north-west of Amarah city (Boakye et al., 2008).

\section{MATERIALS AND METHODS}

\section{DGPS Setting}

For this study, six datasets had to be generated. It included: (i) several digital contours for interpolation into a DEM from the largest mapping possible, (ii) a digital photogrammetry DEM, and (iii) several DGPS points. They included: Two data sets, one from each of the

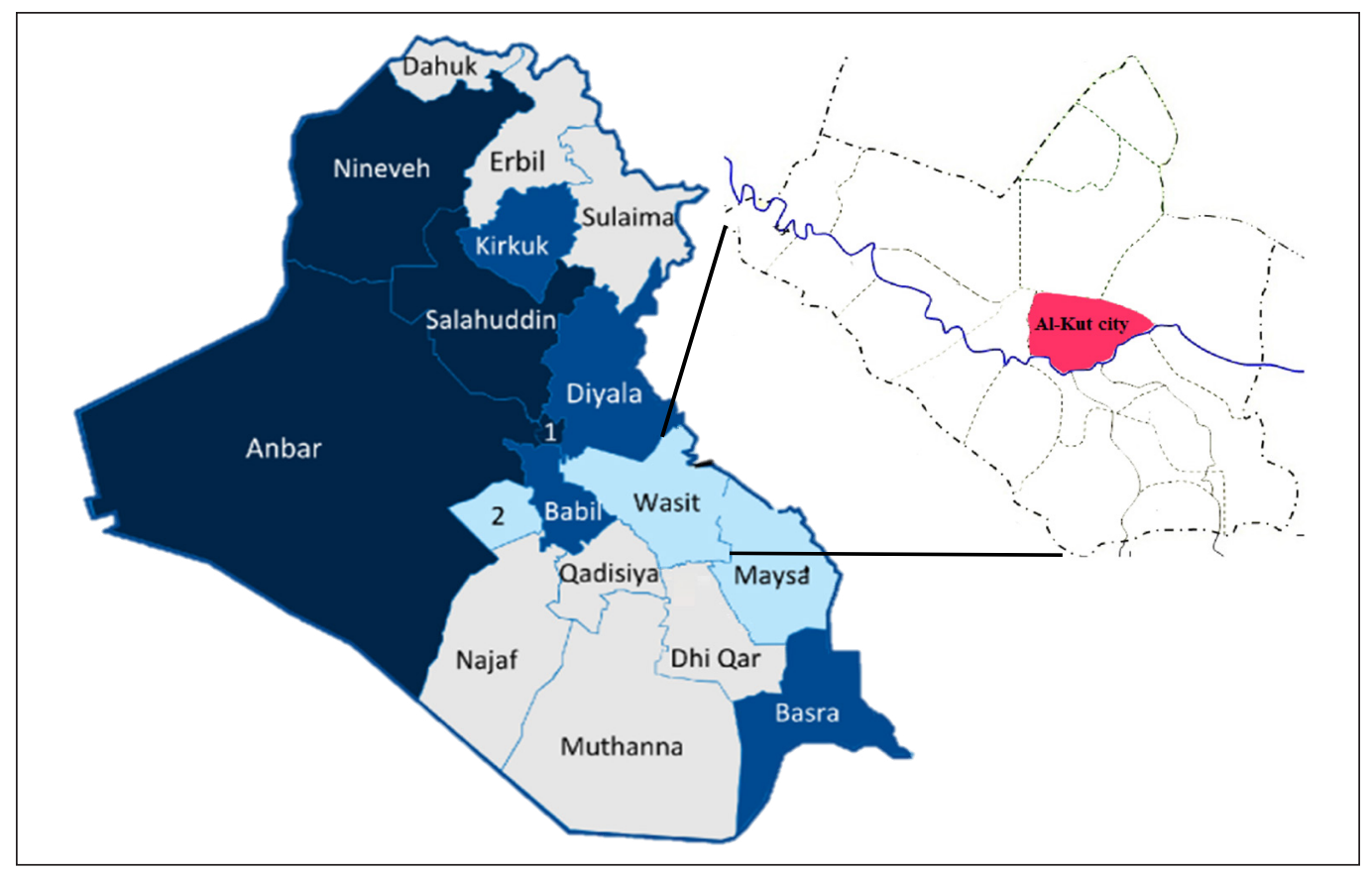

Figure 1. Al-Kut city location within the Wassit Governorate of Iraq 
areas of study that were needed. On-screen from the map Ordnance Survey (OS) 1:25000 digitized contours for the KUT region of the study have been digitized. In order to avoid interpolatory border mistakes, a wide margin across the study region is digitized. These contours were digitized via ArcView and then used as a polyline input into the module feature Spatial Analyst.

The three datasets for the Iraqi field of research were developed as the KUT data datasets. Onscreen digitization of 1:10000 maps was given as black and white scanned images. The digital contour data was extracted. In order to minimize interpolation errors in the analysis, a large margin has been digitized across the sample region. The distance between contours on these maps was 10 meters. The same processes mentioned for the KUT data set were followed by interpolation, transformation, and import into imaginary. The digital photogrammetric extraction of data from 1996 for the region of the Iraqi analysis was carried out using OrthoMax software in 1:12000 color aerial photography. Ground correction control was based upon 1:25000 maps because when digital photogramming was performed, a 1:10000 map was not usable. The performance error was considerably higher than in KUT photogrammetry due to the smaller photography size and poor accuracy of maps used.

\section{Procedure of Calculation}

In the first step, the $\mathrm{x}$ and $\mathrm{y}$ coordinates of the points to be analyzed were established. The GPS dataset consultation decided it. The Imagine function was then used to obtain from the relevant points the interpolated and photogrammetric height values. The method output was the $\mathrm{X}, \mathrm{Y}$, and $\mathrm{Z}$ text files for the points. For collection and statistical analysis, these files were imported into Microsoft Excel.

Different statistics, including maximal error, average (mean) error, and RMSE, can be obtained by directly comparing the height values for the three datasets. Excel also permitted the constructing plots of the points that, when analyzed in addition to field notes, allowed the precise evaluation of high error points or areas and the potential cause for the postulation of error.

\section{Detection and Analysis of Land}

Three QuickBird $60 \mathrm{~cm}$ global high-resolution satellite images from 1997, 2007, and 2017 were acquired from the United States Geological Survey (USGS). Digital images were processed using conventional processes as follows; (i) ENVI 4.7 suite of programs were used to clip the region of interest in this research (Dewan \& Yamaguchi, 2009) (ii) the satellite images were radiometrically corrected using geo-referencing methods for subsequent GIS data integration, and finally, (iii) images were enhanced using Erdas imagine 2014 software. 
Each scene was geo-referenced using nine ground control points (GCPs) identified and selected from the Differential Global Positioning System (DGPS), followed by using the corrected image as a reference for image-to-image registration of all other band-images. The random distortion technique was used to correct the pictures geometrically (Kim et al., 2017). For a general knowledge of the study area, the research was supported by field survey inquiry.

\section{RESULTS AND DISCUSSION}

\section{Detection in the Urban Land-Use Area}

Table 1 shows that the town of Al-Kut has a significant spatial change based on the visual interpretation of high-resolution satellite pictures by spatial resolution ( $1 \mathrm{~m}$ and $0.6 \mathrm{~m})$ and spatial resolution (30 m) land satellite images for that city during the period 1997-2017.

Based on the analysis from the outcomes, the first ten years (from 1997-2007). The total area of the urban area in 1997 was 8376.299 hectares, compared to 5824.057 hectares at the end of 2007. At the end of 2017, 12711.035 hectares were recorded. The total area changes for the period 1997-2017 were 4891.984 hectares. This expansion came from several variables, and the most important variable is the increase in population and migration, where the population size of 1997 was 340 thousand, up to 2017 estimates showing the population size of the town 457 thousand, this may result in changes in the type or pattern of use based on scheduling, political, social and other factors (Mengistu \& Salami, 2007).

Table 1

The percentage of Land use / Land cover change analysis in AL-Kut city in 1997, 2007, and 2017

\begin{tabular}{|c|c|c|c|c|c|c|c|c|}
\hline \multirow[b]{2}{*}{ Type of use } & \multicolumn{2}{|c|}{ Year 1997} & \multicolumn{2}{|c|}{ Year 2007} & \multicolumn{2}{|c|}{ Year 2017} & \multicolumn{2}{|c|}{ Amount of change } \\
\hline & $\begin{array}{c}\text { Area } \\
\text { (hectare) }\end{array}$ & $\begin{array}{l}\text { Value } \\
(\%)\end{array}$ & $\begin{array}{c}\text { Area } \\
\text { (hectare) }\end{array}$ & $\begin{array}{l}\text { Value } \\
(\%)\end{array}$ & $\begin{array}{c}\text { Area } \\
\text { (hectare) }\end{array}$ & $\begin{array}{c}\text { Value } \\
(\%)\end{array}$ & $\begin{array}{c}\text { Area } \\
\text { (hectare) }\end{array}$ & $\begin{array}{l}\text { Value } \\
(\%)\end{array}$ \\
\hline Residential & 1720.107 & 13.513 & 3581.475 & 28.135 & 7126.432 & 55.984 & 5406.325 & 314.301 \\
\hline $\begin{array}{l}\text { Commercial } \\
\text { market }\end{array}$ & 38.492 & 0.302 & 62.365 & 0.489 & 80.410 & 0.631 & 41.918 & 108.900 \\
\hline Industrial & 48.548 & 0.381 & 50.698 & 0.398 & 154.962 & 1.217 & 106.414 & 219.193 \\
\hline $\begin{array}{l}\text { Agricultural } \\
\text { lands }\end{array}$ & 6804.550 & 53.456 & 3986.049 & 31.314 & 2285.406 & 17.954 & -4519.144 & -66.413 \\
\hline Vacant land & 3841.701 & 30.180 & 4655.963 & 36.577 & 2604.967 & 20.464 & -1236.734 & -32.192 \\
\hline Services & & & & & & & & \\
\hline Educational & 65.866 & 0.517 & 87.822 & 0.689 & 89.760 & 0.705 & 23.894 & 36.276 \\
\hline Recreation & 161.881 & 1.271 & 253.373 & 1.99 & 324.932 & 2.552 & 163.051 & 100.722 \\
\hline $\begin{array}{l}\text { Religious } \\
\text { places }\end{array}$ & 1.081 & 0.008 & 1.081 & 0.008 & 1.371 & 0.010 & 0.290 & 26.857 \\
\hline Hospitals & 46.976 & 0.369 & 50.376 & 0.395 & 60.962 & 0.478 & 13.986 & 29.772 \\
\hline Sum & 12729.202 & 100 & 12729.202 & 100 & 12729.202 & 100 & 0 & 737.416 \\
\hline
\end{tabular}




\section{Change Detection in the Residential Area}

Table 1 and Figure 2 indicate that residential use has seen a substantial shift in the area for the period 1997-2017 because of urban expansion, which is one of the reasons that contributed to the land investment has changed, especially the encroachment on land near the city. It is evident in the change in the category of positive use at the expense of agricultural lands and empty spaces, which is used occupied 1486.107 hectares, $12.464 \%$ in 1997, a small area relatively due to the small population that affected the residential space and area. During that period, the area allocated for residential use increased by $19.107 \%$ from 2007 to 1981.475 hectares, a small area compared with 1997. In 2017, a remarkable increase was observed while the area of the city recorded 6026.432 hectares, with $47.302 \%$ of the city's total area. It is due to a change in the category of positive residential use and its expansion at the expense of empty spaces and agricultural land. Years and the period of economic siege imposed on the Iraqi people, which lasted over 13 years, so that the slight increase in the area is justified, including regulatory, political and population, and other factors (Abd El-Kawy et al., 2011; Verburg et al., 2011)

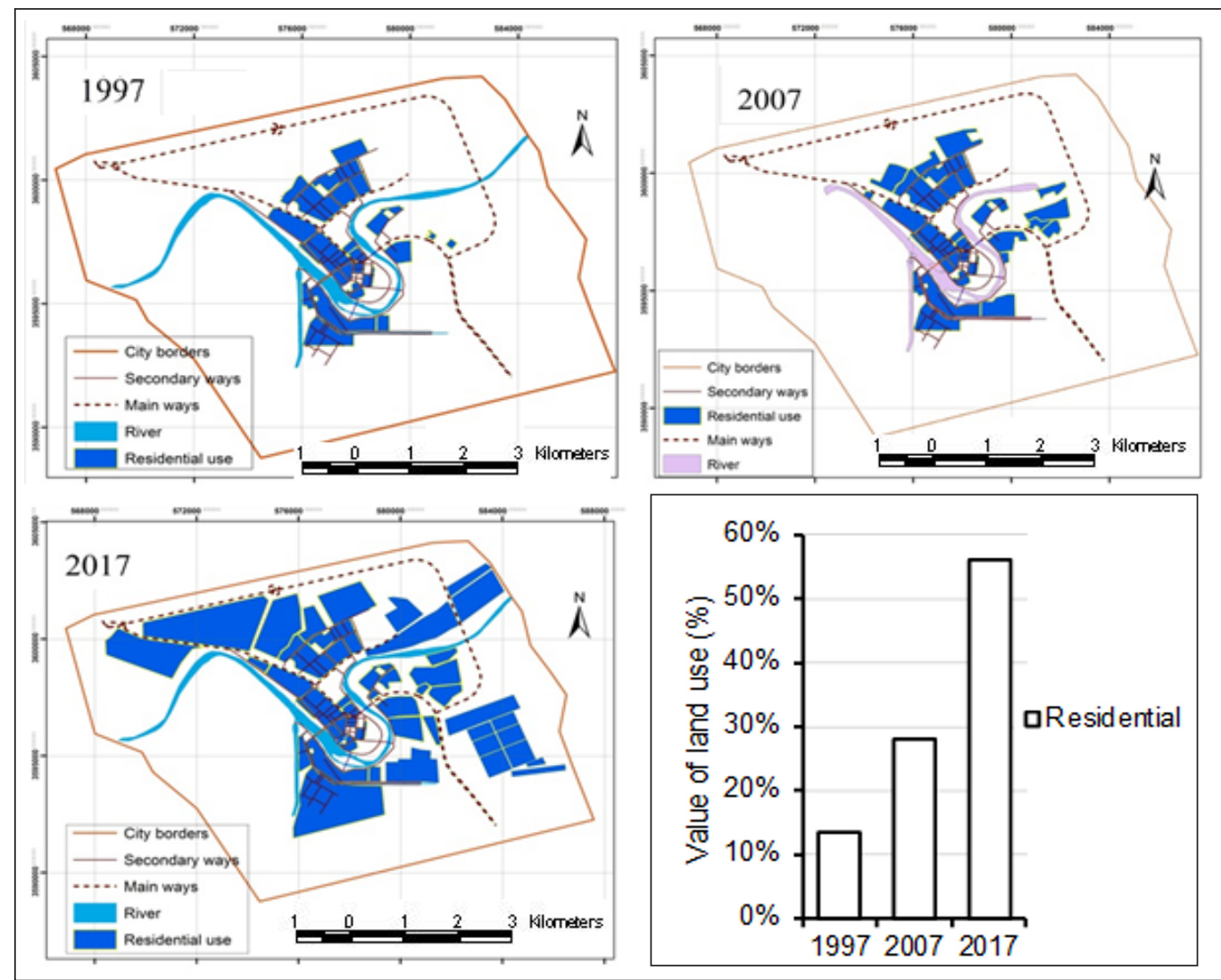

Figure 2. The changes of areas for residential use in Al-Kut city in 1997, 2007, and 2017, and the percentage of residential use change over the same period 
The reason for the increase in the area in the combination of many variables coincided with the change of the system in 2003 and its consequences for the deterioration of the security situation and the weakness of the regulators, which encouraged many of the population, particularly from the southern and central provinces and even the North, including the mass exodus to the province of Kut, for two reasons first the state of security calm in the city of Kut, compared to other governorates and second, the economic side, to work and earn a daily living. As a result, the clear increase in the residential area changes for the period 1997-2017 can be seen, noting that the residential area registered an absolute positive change of 4540.325 hectares at a rate of change of $305.518 \%$.

\section{Change Detection in the Commercial Area}

The urban expansion in cities is a land change that affects all uses without exception, depending on the importance of this use (Halefom et al., 2018). Therefore, land uses are expanding simultaneously with the expansion of other uses, thus showing a mixture of land uses, including residential, service, industrial, and even commercial. For example, Table 1 and Figure 3 show that, during the period 1997-2017, the commercial use covered the change in the field with a record area of 38.492 hectares by $0.322 \%$ in 1997 . However, the positive spatial change of this use soon began until the record 45.365 hectares increased by $0.437 \%$ in 2007 despite the circumstances of the eight-year war. After that, however, the rate of change in the commercial area increased as a result of a creation of a new revival.

In 2017, for political and economic reasons, the commercial area registered 80.4106 hectares at a rate of $0.631 \%$. From the above, the absolute change in the commercial area is moving towards a positive record of 41.919 hectares with a change rate of $108.903 \%$. This rate is high due to the excessive commercial use of agricultural and empty spaces calculations and changes in housing units, which have changed from the category of use because they have been cut off and annexed for commercial use. However, institutions and commercial markets have rapidly developed over time to the present study, which covers all parts of the city, or the outskirts of the city, or outside the residential neighborhoods (Paul et al., 2016).

\section{Change Detection in the Industrial Area}

The present form of distribution of industrial land use is not the result of coincidence; however, it is governed by several factors, including site, land, planning, transport, political and other factors, to achieve the current distribution (Bajocco et al., 2012). Thus, in Table 1 and Figure 4, industrial use reported an area of 48.548 hectares by $0.407 \%$ in 1997 . However, this increase did not last long but recorded a significant decline during the 1990s following the imposition of economic sanctions (economic blockade and its consequences), which led to the suspension of many industrial projects primarily based on raw materials 


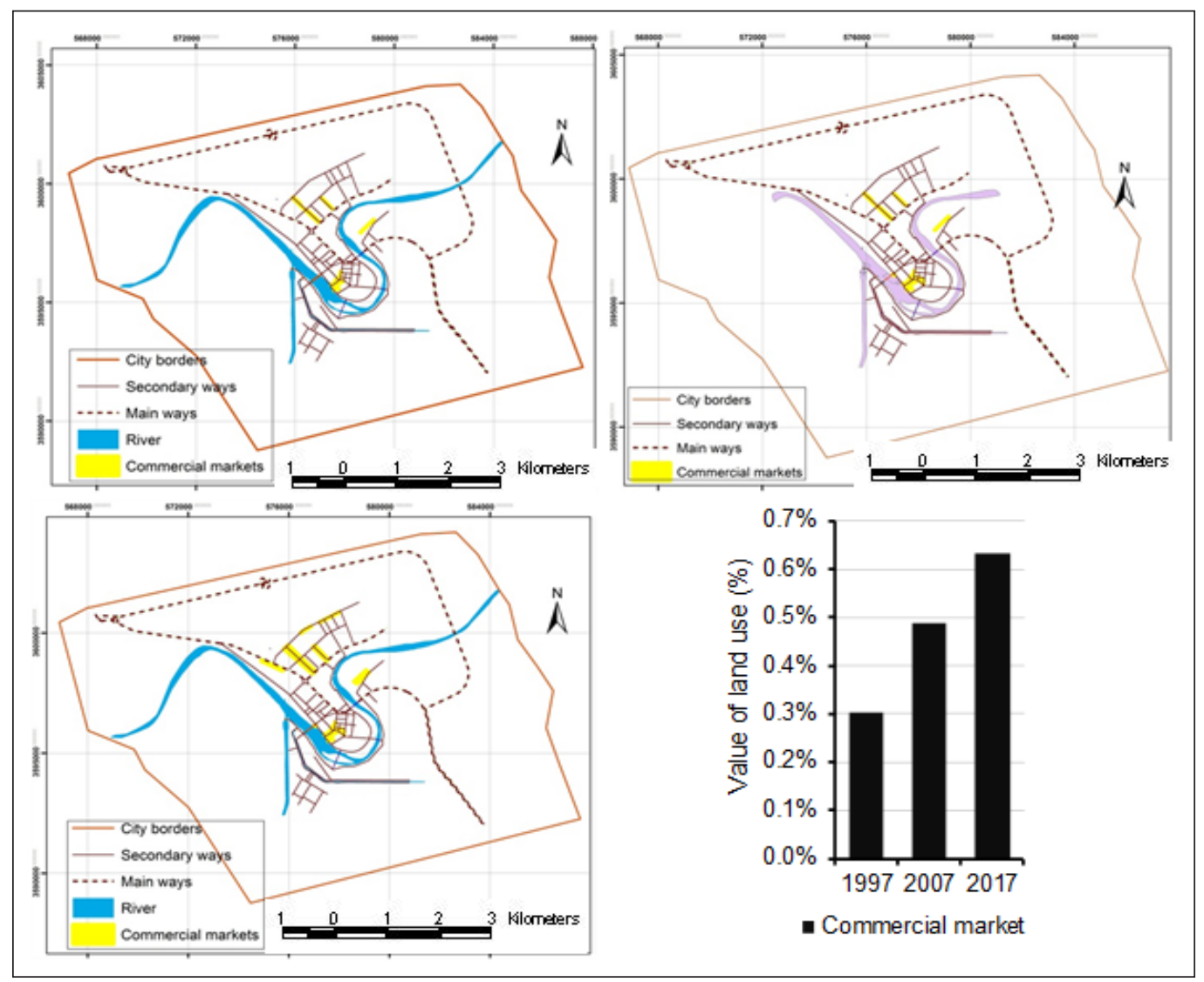

Figure 3. The changes of areas for commercial use in Al-Kut city in 1997, 2007, and 2017, and the percentage of commercial use change over the same period

imported from the outskirts, the industrial use area was 48.548 hectares in 2007 and a $437 \%$ increase in the area allocated for industrial use in 2017 to increased to $1.216 \%$ of the urban area of 154.962 hectares. It is due to the lifting of the economic sanctions imposed on Iraq and the diversification of industrial products received in the country, especially after the regime changed in 2003. In general, the amount of change in industrial use was recorded +106.414 hectares by the change rate of $219.193 \%$.

\section{Change Detection in the Service Area}

Figure 5 show that there has been a noticeable change in the uses of service land (educational, health, religious, and recreation), particularly with the rise in the area allocated to each of the two dates. Table 1 shows an increase in the rate of change area for service uses. Therefore, the area changes, and the rate of increase changes during the study periods, shifting towards the positive. For example, the change in Education services is $36.276 \%$, health is $31.389 \%$, religion is $26.827 \%$, and recreation is $102.634 \%$. 


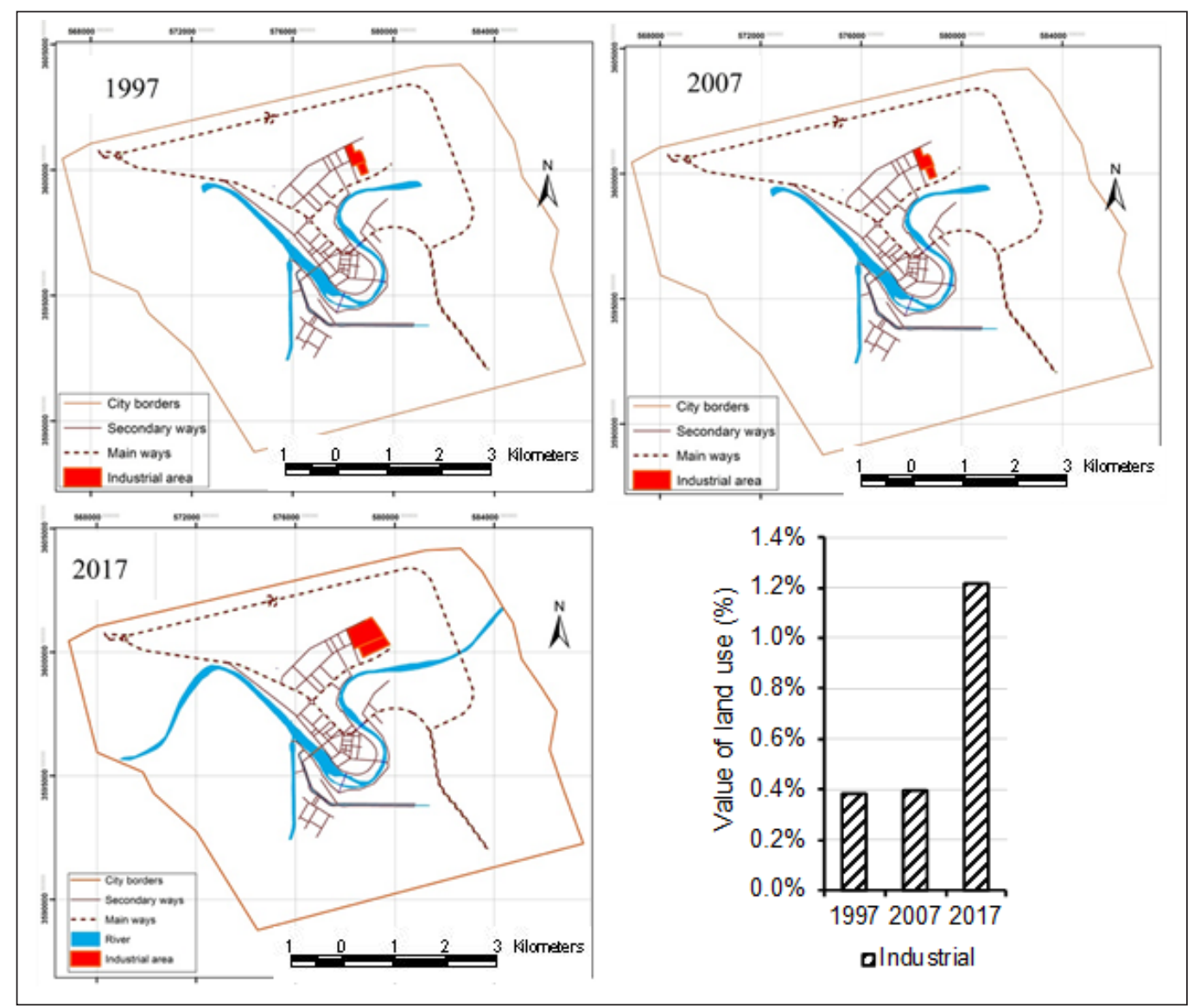

Figure 4. The changes of areas for industrial use in Al-Kut city in 1997, 2007, and 2017, and the percentage of industrial use change over the same period

\section{Change Detection in the Agricultural Area}

Through remote sensing software and satellite image interpretation, it appears that the green area in the northern part of the city and some scattered areas that existed in the 1970s have decreased significantly, as shown in Table 1, which indicates the extent of change in agricultural land. The agricultural land area occupied 6529.453 hectares by $54.763 \%$ in 1997 . The area decreased to 2285.406 hectares and $17.938 \%$ of the total area of the city in 2017 . The absolute land change was recorded in -4244.047 hectares with a rate change of $64.998 \%$. This reduction shows that the urban land use, especially the residential use, has been pushed at the expense of agricultural land, which has reduced the size of the current area, as shown in Figure 6. It can be seen in many areas that are presently residential neighborhoods. It can be noted that residential use is the most widespread use at the expense of agricultural land, and many of them have been fully urban, and the rest are still candidates for such use. 


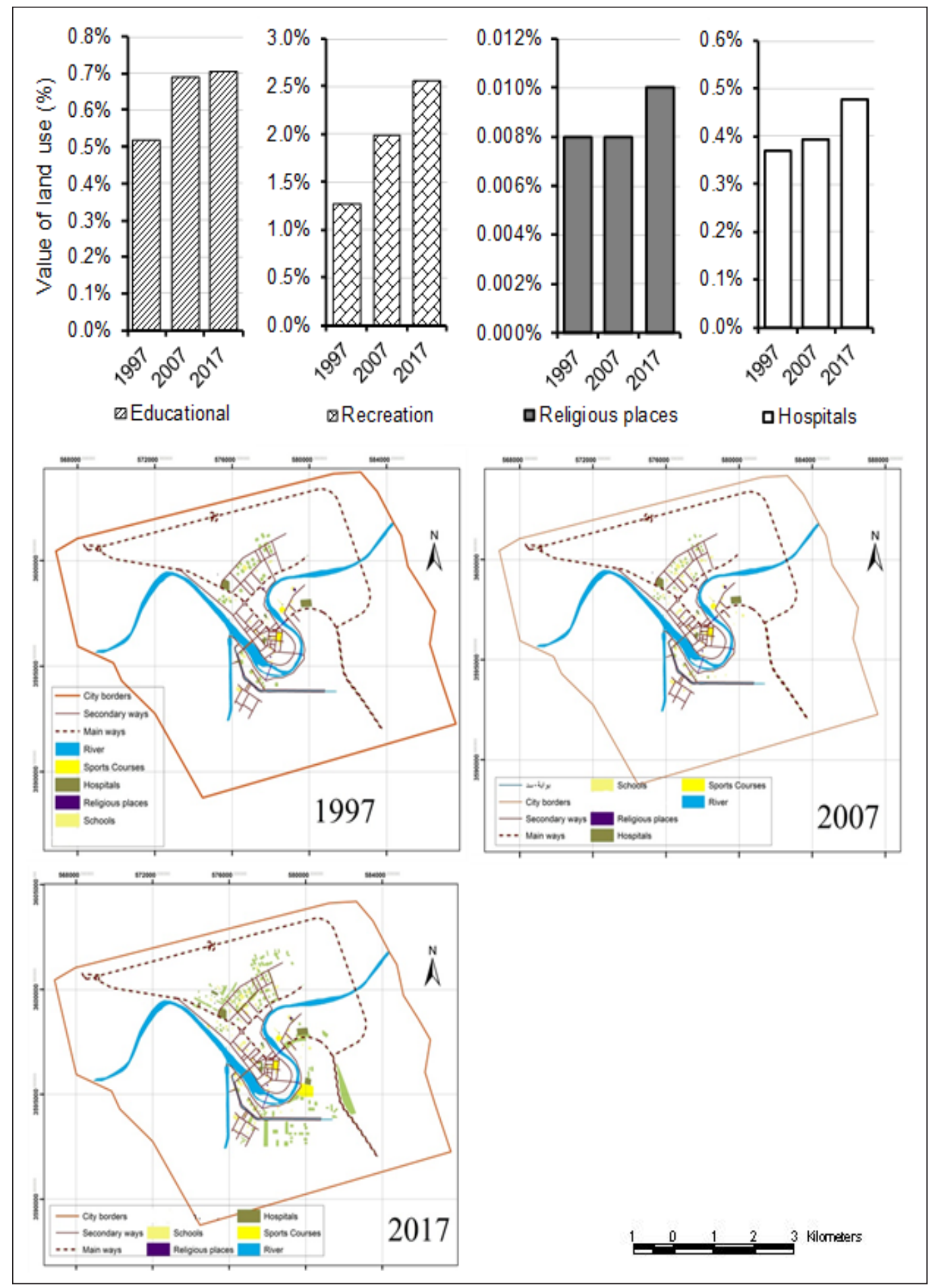

Figure 5. The changes of areas for services use in Al-Kut city in 1997, 2007, and 2017, and the percentage of services changed over the same period 


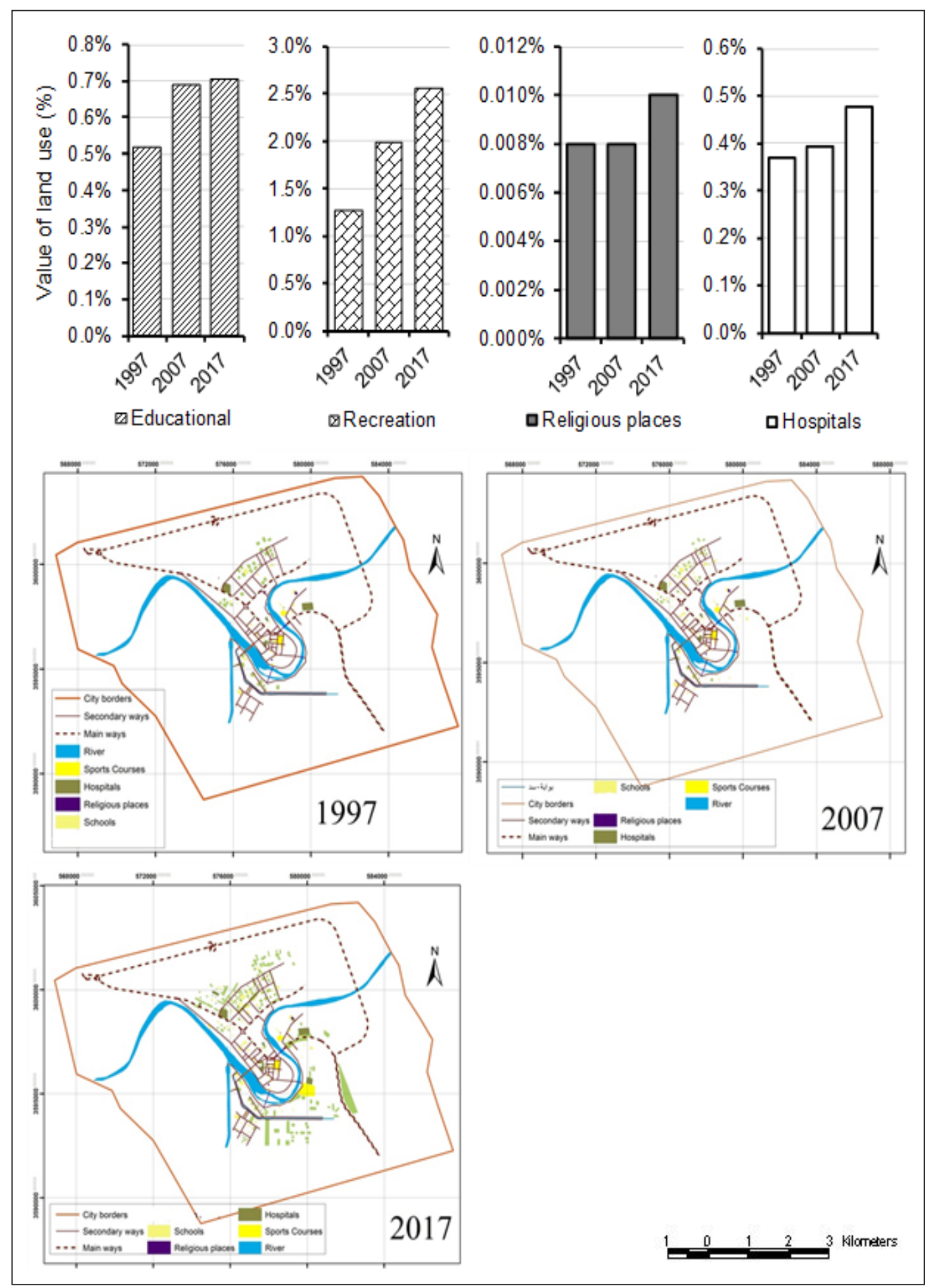

Figure 6. The changes of areas for agricultural use in Al-Kut city in 1997, 2007, and 2017, and the percentage of agricultural use change over the same period 


\section{Change Detection in the Vacant Lands}

As shown in Table 1, the vacant lands of the city have been reduced in area. For example, Figure 7 indicates that the empty space in 1997 was about half of the city's area of 3546.762 hectares and $29.747 \%$ while this area reduced in 2017 to $29.167 \%$ with an area of 3715.967 hectares, so the change in the area was 169.205 hectares with the change rate of $4.77 \%$.

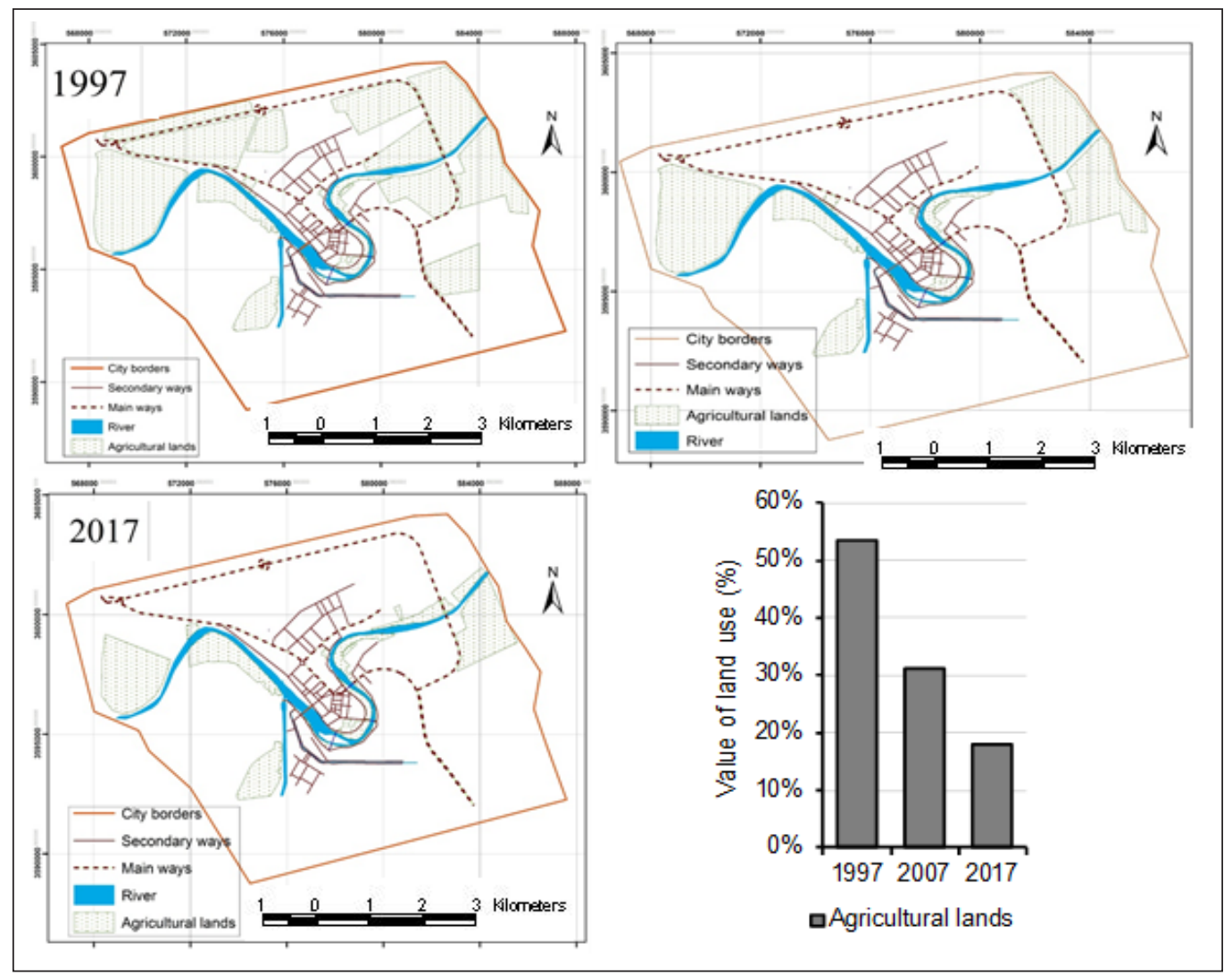

Figure 7. The changes of areas for vacant land in Al-Kut city in 1997, 2007, and 2017, and the percentage of vacant lands change over the same period

\section{CONCLUSIONS}

The study of spatial and digital maps by remote sensing and geographic information systems (GIS) shows that residential use changed in the study period from 1997 to 2017. In 1997, it recorded 1486.107 hectares, which rose to 6026.432 hectares in 2017 with an increase of 4540.325 hectares, which means that the residential use area increased by four times during the mentioned period $305.518 \%$ change.

For several years digital photogrammetry was feasible, but the development of inexpensive and efficient desktop computers has led the technique out of the field of 
science and into daily use. The methodology is now readily accessible, but many people do not know what the solution would be. Error is quantified in the methodology, and its consequences are discussed.

Data used in this analysis were from two areas of temperature, substrates, and relief contrasting to each other. These are the upland floodplains and river terraces in Wales and the topography of the Badlands in a semi-arid Spanish country. This method makes it possible for any procedure in the areas to make a detailed assessment of the absolute elevation error.

The study showed that urbanization, which highlighted the changes in the residential use category, was at the expense of agricultural land and empty spaces. The area of agricultural land, as shown by the NDVI technique of 1997, recorded 6529.453 hectares, with an area of 2285.406 hectares in 2017, With a negative change of 4244.047 hectares with a negative change of $64.998 \%$, while vacant lands recorded in 1997, 3546.762 hectares expanded in 2017 to 3715.967 hectares, which means an absolute change of record of 169.205 hectares with a change of $4.77 \%$.

Recommendation for the future study: There will be a range of additions to expand this work further and enhance the understanding and comparison of DEM sources. It may be interesting to study various interpolation procedures. Although other sources of DEMs would be more helpful as this would increase the confidence of results significantly. The new Shuttle Radar Topographic Mapping data are one source of potential for another DEM. Data will be accessible from this source in the future.

\section{ACKNOWLEDGEMENT}

The authors gratefully thank Ali Asaad Tayeb for his assistance. Also, we would like to thank the governorate of Wasit for their support and providing the satellite images for the study area.

\section{REFERENCES}

Abd El-Kawy, O. R., Rød, J. K., Ismail, H. A., \& Suliman, A. S. (2011). Land use and land cover change detection in the western Nile delta of Egypt using remote sensing data. Applied Geography, 31(2), 483494. https://doi.org/10.1016/j.apgeog.2010.10.012

Bajocco, S., De Angelis, A., Perini, L., Ferrara, A., \& Salvati, L. (2012). The impact of land use/land cover changes on land degradation dynamics: A Mediterranean case study. Environmental Management, 49(5), 980-989. https://doi.org/10.1007/s00267-012-9831-8

Boakye, E., Odai, S. N., Adjei, K. A., \& Annor, F. O. (2008). Landsat images for assessment of the impact of land use and land cover changes on the Barekese catchment in Ghana. European Journal of Scientific Research, 22(2), 269-278. 
Dewan, A. M., \& Yamaguchi, Y. (2009). Using remote sensing and GIS to detect and monitor land use and land cover change in Dhaka Metropolitan of Bangladesh during 1960-2005. Environmental Monitoring and Assessment, 150(1-4), 237-249. https://doi.org/10.1007/s10661-008-0226-5

Halefom, A., Teshome, A., Sisay, E., \& Ahmad, I. (2018). Dynamics of land use and land cover change using remote sensing and GIS: A case study of Debre Tabor Town, South Gondar, Ethiopia. Journal of Geographic Information System, 10(02), Article 83580. https://doi.org/10.4236/jgis.2018.102008

Kim, J., Song, J., No, H., Han, D., Kim, D., Park, B., \& Kee, C. (2017). Accuracy improvement of DGPS for low-cost single-frequency receiver using modified Flächen Korrektur parameter correction. ISPRS International Journal of Geo-Information, 6(7), Article 222. https://doi.org/10.3390/ijgi6070222

Mengistu, D. A., \& Salami, A. T. (2007). Application of remote sensing and GIS inland use/land cover mapping and change detection in a part of south western Nigeria. African Journal of Environmental Science and Technology, 1(5), 99-109.

Paul, S., Ghosh, S., Oglesby, R., Pathak, A., Chandrasekharan, A., \& Ramsankaran, R. A. A. J. (2016). Weakening of Indian summer monsoon rainfall due to changes in land use land cover. Scientific Reports, 6(1), 1-10. https://doi.org/10.1038/srep32177

Popovici, E. A., Bălteanu, D., \& Kucsicsa, G. (2013). Assessment of changes in land-use and land-cover pattern in Romania using Corine Land Cover Database. Carpathian Journal of Earth and Environmental Sciences, 8(4), 195-208.

Prakasam, C. (2010). Land use and land cover change detection through remote sensing approach: A case study of Kodaikanal Taluk, Tamil Nadu. International Journal of Geomatics and Geosciences, 1(2), Article 150.]

Verburg, P. H., Neumann, K., \& Nol, L. (2011). Challenges in using land use and land cover data for global change studies. Global Change Biology, 17(2), 974-989. https://doi.org/10.1111/j.1365-2486.2010.02307.x

Xiao, H., \& Weng, Q. (2007). The impact of land use and land cover changes on land surface temperature in a karst area of China. Journal of Environmental Management, 85(1), 245-257. https://doi.org/10.1016/j. jenvman.2006.07.016 